\title{
Correction
}

\section{Correction: Mittner et al., "When the Brain Takes a Break: A Model-Based Analysis of Mind Wandering”}

In the article "When the Brain Takes a Break: A Model-Based Analysis of Mind Wandering" by Matthias Mittner, Wouter Boekel, Adrienne M. Tucker, Brandon M. Turner, Andrew Heathcote, and Birte U. Forstmann, which appeared on pages 16286-16295 of the December 3, 2014 issue, there was an error in the color code in Figure 3A. The blue bars should be red and the red bars should be blue. This correction does not affect the conclusions of the paper. Figure 3 has been corrected in the online PDF version and is displayed below.
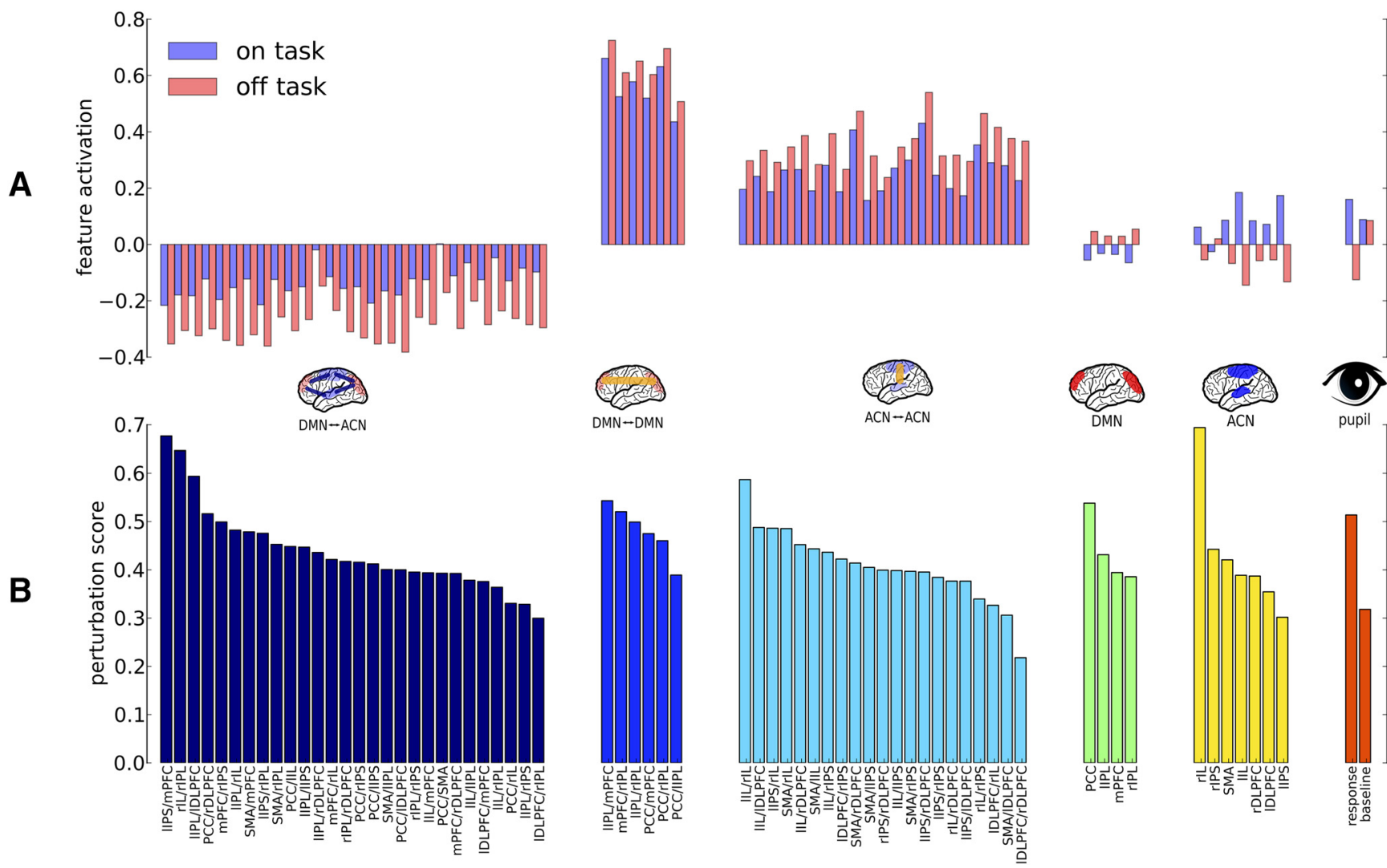

B
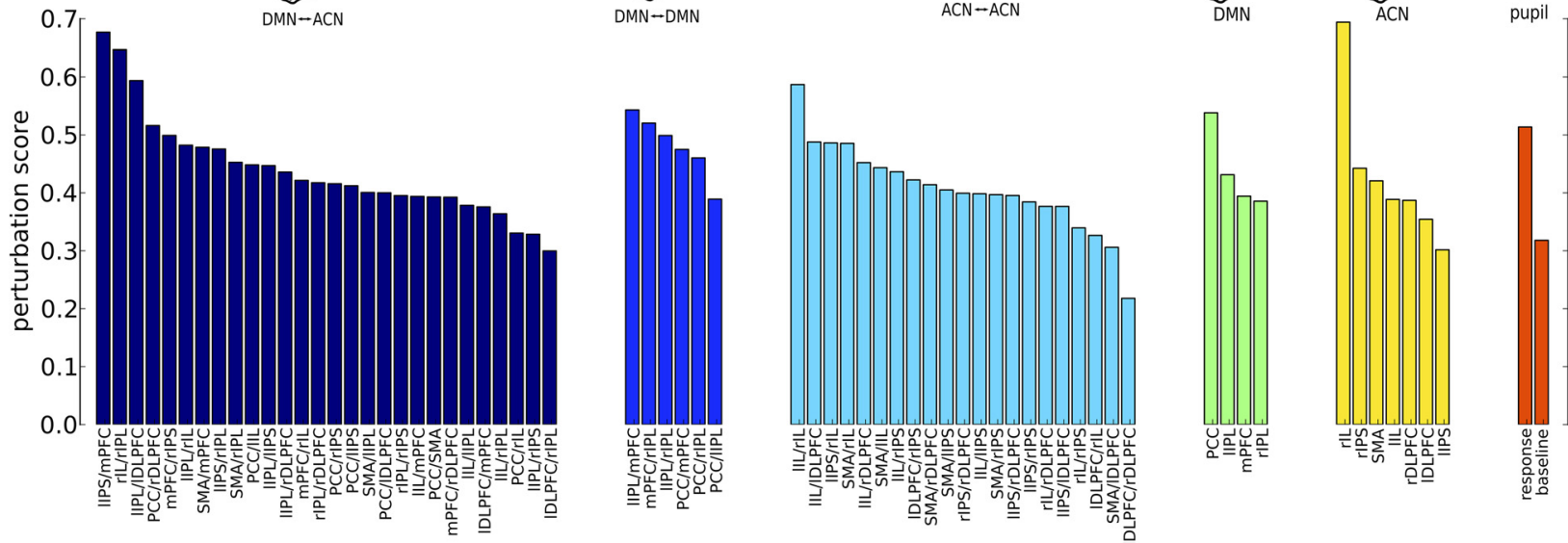

Figure 3. 